\title{
Chemical Proteomics Maps Brain Region Specific Activity of Endocannabinoid Hydrolases
}

Marc P. Baggelaar, ${ }^{\dagger, \|_{\odot}}$ Annelot C. M. van Esbroeck, ${ }^{\dagger, \|}$ Eva J. van Rooden, ${ }^{\dagger}$ Bogdan I. Florea, Herman S. Overkleeft, ${ }^{\ddagger}$ Giovanni Marsicano, ${ }^{\S}$ Francis Chaouloff, ${ }^{\S}$ and Mario van der Stelt ${ }^{*},{ }^{\dagger}$

${ }^{\dagger}$ Department of Molecular Physiology, Leiden Institute of Chemistry, Leiden University, Leiden, The Netherlands

${ }^{*}$ Department of Bio-organic Synthesis, Leiden Institute of Chemistry, Leiden University, Leiden, The Netherlands

${ }^{\S}$ Plateforme de Chimie Analytique, NeuroCentre INSERM U862, Bordeaux, France

Supporting Information

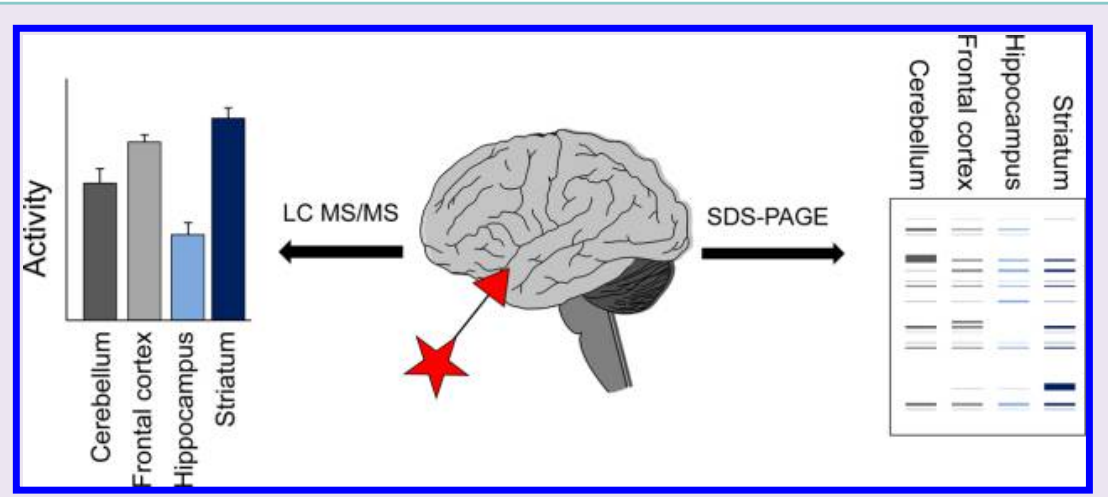

ABSTRACT: The biosynthetic and catabolic enzymes of the endocannabinoids tightly regulate endocannabinoid-mediated activation of the cannabinoid $\mathrm{CB}_{1}$ receptor. Monitoring the activities of these endocannabinoid hydrolases in different brain regions is, therefore, key to gaining insight into spatiotemporal control of $\mathrm{CB}_{1}$ receptor-mediated physiology. We have employed a comparative chemical proteomics approach to quantitatively map the activity profile of endocannabinoid hydrolases in various mouse brain regions at the same time. To this end, we used two different activity-based probes: fluorophosphonate-biotin (FPbiotin), which quantifies FAAH, ABHD6, and MAG-lipase activity, and MB108, which detects DAGL- $\alpha$, ABHD4, ABHD6, and $\mathrm{ABHD} 12$. In total, 32 serine hydrolases were evaluated in the frontal cortex, hippocampus, striatum, and cerebellum. Comparison of endocannabinoid hydrolase activity in the four brain regions revealed that FAAH activity was highest in the hippocampus, and MAGL activity was most pronounced in the frontal cortex, whereas DAGL- $\alpha$ was most active in the cerebellum. Comparison of the activity profiles with a global proteomics data set revealed pronounced differences. This could indicate that post-translational modification of the endocannabinoid hydrolases is important to regulate their activity. Next, the effect of genetic deletion of the $\mathrm{CB}_{1}$ receptor was studied. No difference in the enzymatic activity was found in the cerebellum, striatum, frontal cortex, and hippocampus of $\mathrm{CB}_{1}$ receptor knockout animals compared to wild type mice. Our results are in line with previous reports and indicate that the $\mathrm{CB}_{1}$ receptor exerts no regulatory control over the basal production and degradation of endocannabinoids and that genetic deletion of the $\mathrm{CB}_{1}$ receptor does not induce compensatory mechanisms in endocannabinoid hydrolase activity.

$\mathrm{T}$ he endocannabinoid system consists of the cannabinoid type 1 and $2\left(\mathrm{CB}_{1}\right.$ and $\left.\mathrm{CB}_{2}\right)$ receptors, lipid messengers termed endocannabinoids, and the hydrolytic enzymes responsible for the biosynthesis and catabolism of these lipid signaling molecules. 2-Arachidonoylglycerol (2-AG) and anandamide (AEA) are the two main endocannabinoids. ${ }^{1}$ The $\mathrm{CB}_{1}$ receptor has a relatively high expression in the central nervous system, while the $\mathrm{CB}_{2}$ receptor is more abundant in immune cells. The $\mathrm{CB}_{1}$ receptor is among the most abundant G-protein coupled receptors in the brain and modulates a wide variety of signaling events, including inhibition of adenylate cyclase activity, stimulation of ERK activation, closure of voltage-sensitive $\mathrm{Ca}^{2+}$ channels, and opening of $\mathrm{K}^{+}$channels. ${ }^{2,3}$ Activation of the $\mathrm{CB}_{1}$ receptor is associated with multiple physiological processes, such as energy balance, learning and memory, pain sensation, and neuro-inflammation. ${ }^{4-7}$ Unlike classical polar neurotransmitters, which are stored in presynaptic vesicles, 2-AG and AEA are synthesized "ondemand" from postsynaptic membranes and act as retrograde messengers activating presynaptic $\mathrm{CB}_{1}$ receptors, thereby modulating neurotransmitter release. This implies that the biosynthetic and catabolic machinery of the endocannabinoids tightly regulates $\mathrm{CB}_{1}$ receptor activation. ${ }^{8}$

Received: November 28, 2016

Accepted: January 20, 2017

Published: January 20, 2017 
Several biosynthetic and catabolic endocannabinoid hydrolases control 2-AG and AEA levels (Figure 1). Diacylglycerol

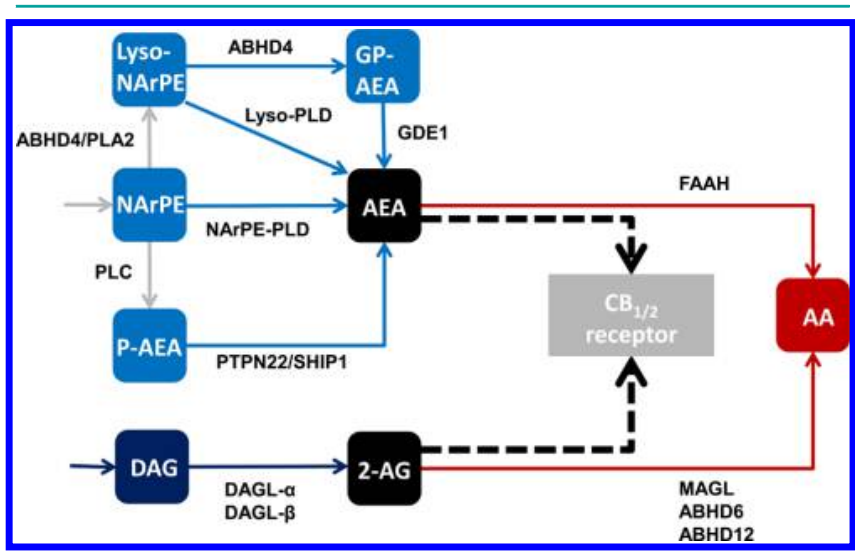

Figure 1. Biosynthetic and catabolic pathways of 2-AG and AEA.

lipase- $\alpha$ and $-\beta$ (DAGL- $\alpha$ and DAGL- $\beta$ ) are the main enzymes producing $2-A G$. They display a tissue specific distribution and studies using mice with congenital deletion of DAGL- $\alpha$ or DAGL- $\beta$ have identified DAGL- $\alpha$ as the primary enzyme responsible for the biosynthesis of 2-AG in the brain. ${ }^{9,10} \alpha, \beta$ Hydrolase-domain-containing protein 6 and 12 (ABHD6 and ABHD12) and monoacylglycerol lipase (MAGL) inactivate 2AG by hydrolysis to give arachidonic acid (AA) and glycerol. MAGL is responsible for the bulk hydrolysis of $2-A G$, while ABHD6 and ABHD12 play a more distinct role in specific cell populations. $^{11}$

The biosynthetic pathways toward AEA appear to be more complex compared with those of $2-\mathrm{AG}^{4,6} \mathrm{~N}$-arachidonoylphosphatidylethanolamine (NArPE) is a key intermediate in AEA biosynthesis. NArPE can be converted via multiple phospholipase-dependent pathways to AEA: (a) hydrolysis by $\mathrm{N}$-acylphosphatidylethanolamine-phospholipase D (NAPEPLD), a metallo- $\beta$-lactamase, producing AEA and a phosphatidic acid in one step ${ }^{12}$ and $(b)$ phospholipase $\mathrm{A}_{2}\left(\mathrm{PLA}_{2}\right)$ and $\alpha, \beta$-hydrolase domain-containing protein 4 (ABHD4) mediated conversion to lyso-NArPE, followed by the action of an unknown lysophospholipase D (PLD). Of note, lyso-NArPE can also be converted in a two-step sequence by ABHD4 to glycerophospho-AEA (GP-AEA) and subsequently hydrolyzed to AEA by glycerophosphodiesterase 1 or 4 (GDE1 or GDE4); ${ }^{13,14}(c)$ in macrophages, NArPE serves as a substrate for an unidentified phospholipase $C$ yielding phospho-AEA. Hydrolysis of the phosphate group by the phosphatases, PTPN22 or SHIP1, provides AEA. ${ }^{15,16}$ The enzymatic inactivation of AEA is less complex and is primarily mediated by fatty acid amide hydrolase (FAAH), which hydrolyses AEA toward arachidonic acid and ethanolamine.,17

The ability to monitor the activity of the different endocannabinoid hydrolases in various brain regions is key to gaining insight in spatiotemporal control of $\mathrm{CB}_{1}$ receptor activation and its physiological role. The existence of a feedback mechanism in anterograde neurotransmitter systems through presynaptic "autoreceptors" to control the release of the neurotransmitters has led to the hypothesis that such an autoregulatory mechanism could also be present in retrograde systems, such as the endocannabinoid system. ${ }^{18-20}$ Previous studies have investigated the effect of $\mathrm{CB}_{1}$ receptor modulation on basal endocannabinoid levels. Several studies observed changes in AEA and/or 2-AG levels, ${ }^{21-25}$ whereas others did not. $^{18,26}$ Interestingly, Maccarrone et al. found that the endocannabinoid system of $\mathrm{CB}_{1}$ knockout mice adapted with age by upregulating AEA catabolism. ${ }^{23,24}$ Recently, Belluomo et al. reported that the MAGL inhibitor JZL-195 reduced 2-AG accumulation rates in the frontal cortex of mice lacking the $\mathrm{CB}_{1}$ receptor in glutamatergic neurons and an increase of 2-AG accumulation under the same conditions in mice with congenital deletion of the $\mathrm{CB}_{1}$ receptor in astrocytes. ${ }^{18}$ In addition, chronic elevation of 2-AG levels by genetic deletion of MAGL or repeated administration of JZL184 led to $\mathrm{CB}_{1}$ receptor desensitization. ${ }^{27}$ These observations suggest the existence of crosstalk between the $C_{1}$ receptor and the endocannabinoid regulatory machinery. The pre- and postsynaptic autoregulatory mechanisms controlling endocannabinoid levels are, however, poorly understood.

Changes in bulk endocannabinoid levels do not reveal which biosynthetic or catabolic pathways are responsible for the regulation of $\mathrm{CB}_{1}$ activity. ${ }^{18,26}$ To this end, the activity of each hydrolytic enzyme should be studied. Over the years, a brain region and cell type resolved map of the molecular distribution of endocannabinoid hydrolases has been generated by in situ hybridization and global proteomics. ${ }^{28-30}$ These studies provided a detailed understanding of the molecular composition of the endocannabinoid system in different brain regions at the mRNA and protein level. However, actual enzymatic activity does not always correlate with mRNA and protein levels in specific brain regions due to post-transcriptional and post-translational processes. ${ }^{31,32}$ The activity of DAGL- $\alpha$ is, for example, regulated by CaMKII-mediated phosphorylation, and MAGL activity can be modulated by sulfenylation of specific cysteines. ${ }^{33,34}$ Consequently, it is important to measure actual enzyme activity in the various brain regions.

Conventional enzyme activity assays rely on radiolabeled substrates and LC/MS-based methods. ${ }^{35}$ These assays are expensive and time-consuming and measure the activity of one enzyme at a time. Others and we have recently applied comparative activity-based protein profiling (ABPP) and chemoproteomics to measure serine hydrolase activity in complex proteomes. ${ }^{36-39} \mathrm{ABPP}$ is a technique pioneered by Cravatt et al., which relies on active site directed chemical probes that react, in a mechanism based fashion, with the catalytic nucleophile of targeted enzymes. The probe establishes a covalent bond with the catalytically active protein and therefore reports on the abundance of active enzymes. Activity-based probes (ABPs) generally have a fluorescent or biotin reporter group for visualization and identification, respectively. ${ }^{36}$ Many enzymes regulating brain endocannabinoid levels, including MAGL, DAGL, FAAH, ABHD4, ABHD6, and $\mathrm{ABHD} 12$, belong to the serine hydrolase family; therefore they have conserved structural features, which allow for their targeting by specific ABPs, such as FP-TAMRA and MB064. Here, we have used ABPP to map the relative activity of endocannabinoid hydrolases in different brain regions, such as cerebellum, frontal cortex, hippocampus, and striatum. We applied this method to investigate the existence of an autoregulatory feedback mechanism of the $\mathrm{CB}_{1}$ receptor on the endocannabinoid hydrolase activity by comparing the brains of $\mathrm{CB}_{1}$ receptor knockout mice versus wild-type mice.

\section{RESULTS AND DISCUSSION}

Gel-based Brain Region Comparison. Previously, a $\beta$ lactone (MB064) and fluorophosphonate (FP-TAMRA) were applied as tools to study the selectivity of the DAGL inhibitors 


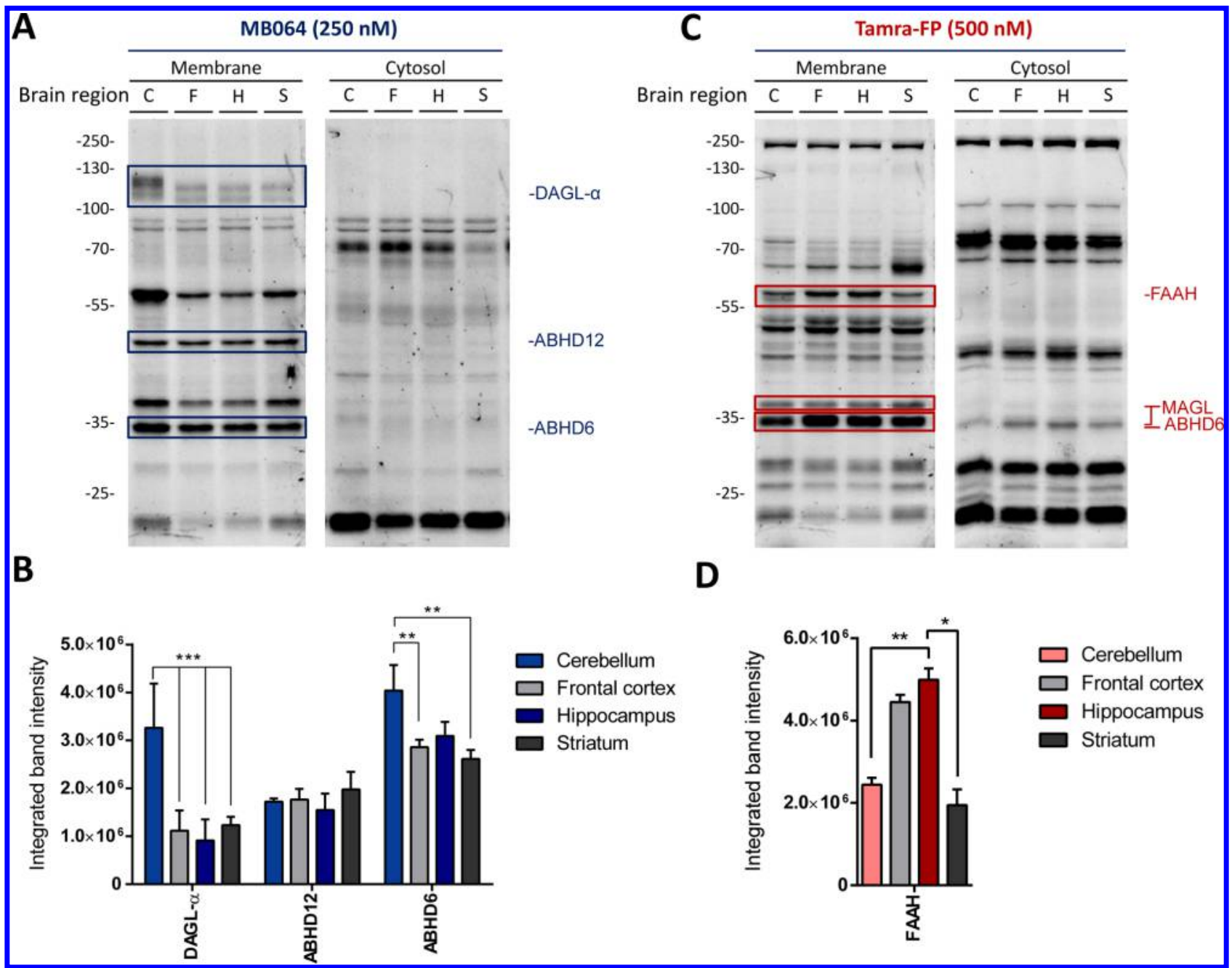

Figure 2. Gel-based mapping of brain region dependent hydrolase activity. (A) Activity-based protein profiling with MB064 in four mouse brain regions. (B) Quantification of endocannabinoid hydrolase activity as determined with MB064 (mean \pm SD; $n=3$ ). (C) Activity-based protein profiling with FP-TAMRA in four mouse brain regions. (D) Quantification of FAAH activity as measured with ABP FP-TAMRA (mean \pm SD; $n=$ 3). Statistical analysis was performed by means of two-way ANOVA with Tukey multiple comparisons test $(* P \leq 0.05$; $* * P \leq 0.01$; ***P $\leq 0.001$; C = cerebellum, $\mathrm{F}=$ frontal cortex, $\mathrm{H}=$ hippocampus, $\mathrm{S}=$ striatum). Integrated band intensity is corrected for protein loading (coomassie).

LEI104, LEI105, and DH376. ${ }^{38,40}$ The use of two ABPs extends the range of enzymes, because the probes have orthogonal warheads and different recognition elements, leading to a different interaction profile. Here, both ABPs were used to map brain region dependent activity of endocannabinoid hydrolases by comparative ABPP. Global assessment of serine hydrolase activity across four different brain regions was performed using a gel-based assay. Membrane and soluble proteomes from mouse cerebellum, frontal cortex, hippocampus, or striatum were incubated with MB064 (250 nM) or FP-TAMRA (500 $\mathrm{nM}$ ) and resolved on SDS-PAGE, and the in-gel fluorescence was analyzed. Coomassie staining was used as a protein loading control. Using MB064, nine intense bands were identified in the membrane fractions of the mouse brain regions, and the identity of endocannabinoid hydrolase bands could be established using reference inhibitors and $\mathrm{KO}$ tissue as previously reported. ${ }^{38,40}$

In this manner, the bands at $120 \mathrm{kDa}, 45 \mathrm{kDa}$, and $35 \mathrm{kDa}$ were ascribed to DAGL- $\alpha$, ABHD12, and ABHD6, respectively. FP-TAMRA labeled FAAH (64 kDa), MAGL (35 and $38 \mathrm{kDa}$ ), and ABHD6 $(35 \mathrm{kDa})$. All identified endocannabinoid proteins were present in the four brain regions, but several hydrolases demonstrated pronounced region-dependent activity (Figure 2 ). For example, DAGL- $\alpha$ activity was $\sim 3$ times higher in the cerebellum compared to the frontal cortex, hippocampus, and striatum (Figure 2A,B). Interestingly, the fluorescent protein band corresponding to DAGL- $\alpha$ in the cerebellum was shifted toward a higher molecular weight compared to the hippocampus, striatum, and frontal cortex. This could indicate that DAGL- $\alpha$ carries a post-translational modification. The activity of $\mathrm{ABHD} 12$ was similar in all four brain regions, while the activity of ABHD6 was $\sim 25 \%$ higher in the cerebellum compared to the frontal cortex, hippocampus, and the striatum. The fluorophosphonate-based $\mathrm{ABP}$ revealed the activity of FAAH to be $\sim 2$ times higher in the frontal cortex and the hippocampus compared to the cerebellum and striatum. The signals of MAGL and ABHD6 as measured with this activitybased probe are overlapping and could not be quantified independently (Figure 2C).

Chemoproteomic Brain Region Comparison. To analyze the relative activities in depth, ABPP was coupled to high resolution mass spectrometry. This methodology enables direct identification of the enzymes and provides a more accurate quantification by avoiding band overlap and yields a 


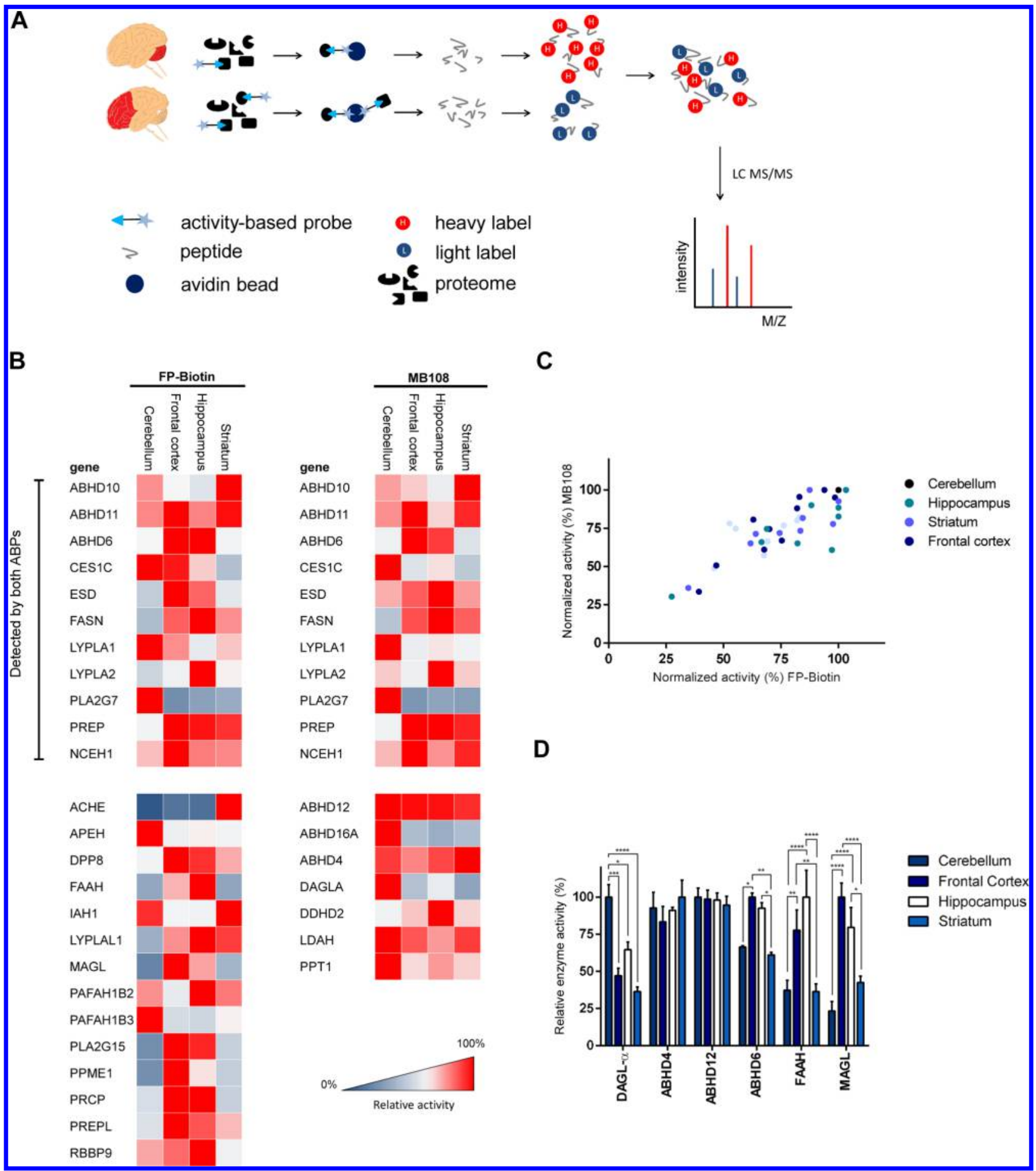

Figure 3. Brain region dependent chemoproteomic mapping of relative hydrolase activity. (A) Schematic representation of the chemoproteomic workflow. (B) Heat map of relative enzyme activity as measured by a fluorophosphonate (FP)-based activity-based probe conjugated to a biotin reporter tag (FP-biotin) and a $\beta$-lactone-based activity-based probe conjugated to a biotin reporter tag (MB108). Data are calculated from the mean ratios of the comparison between cerebellum and striatum, frontal cortex and striatum, and cerebellum and hippocampus. Each comparison was performed in three biological replicates. The relative enzyme activity in the brain region in which the serine hydrolase displayed highest activity was set to $100 \%$. (C) Correlation graph for enzymes detected by both MB108 and FP-biotin. (D) Endocannabinoid regulating enzymes show significant difference between the studied brain regions (mean \pm SEM; $n=3$ ). Statistical analysis was performed by means of two-way ANOVA with Tukey multiple comparisons test $(* P \leq 0.05$; ** $P \leq 0.01$; *** $P \leq 0.001$; **** $P \leq 0.0001)(\mathrm{C}=$ cerebellum, $\mathrm{F}=$ frontal cortex, $\mathrm{H}=$ hippocampus, $\mathrm{S}=$ striatum).

broader range of hydrolases due to a higher sensitivity. Membrane and soluble proteomes from cerebellum, hippocampus, frontal cortex, or striatum were separately incubated with MB108 or FP-biotin, biotinylated versions of MB064 and FP-TAMRA, respectively. Targeted enzymes were enriched by avidin chromatography, followed by on-bead digestion using 


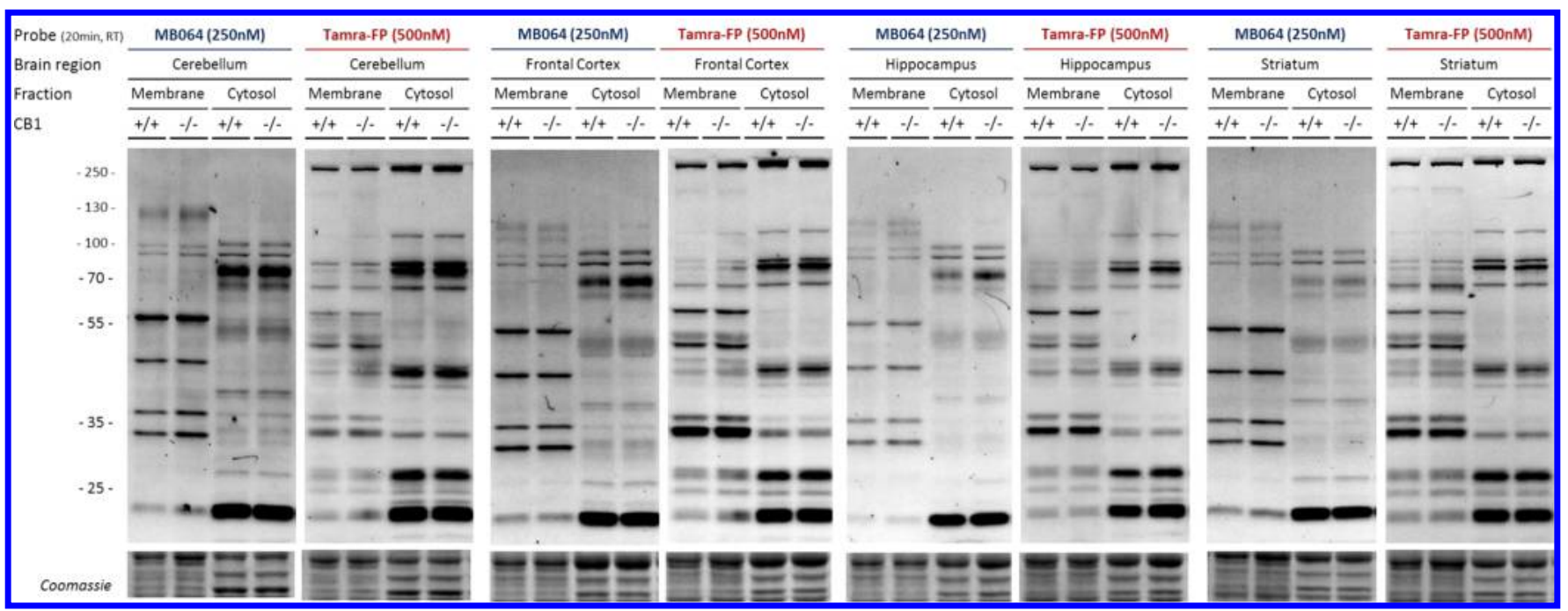

Figure 4. Gel based $\mathrm{CB1}^{+/+}$vs $\mathrm{CB}^{-/-}$comparison. Study of enzyme activity in $\mathrm{CB1}^{+/+}$and $\mathrm{CB1}^{-/-}$mouse brain regions as measured by two activity based probes (MB064 and TAMRA-FP, $n=3$ ). No difference in enzyme activity between $\mathrm{CB} 1^{-/-}$and $\mathrm{CB}^{+/+}$was observed.

sequencing grade trypsin. Tryptic peptides from different brain regions were isotopically labeled by reductive dimethylation with deuterated or nondeuterated formaldehyde. After 1:1 mixing of the differentially labeled brain regions, samples were measured by high resolution MS/MS and analyzed using Maxquant software (a schematic overview of the chemoproteomic workflow is given in Figure 3A). ${ }^{41}$

Using this chemoproteomic methodology, the relative activity of 33 different serine hydrolases was quantified in all brain regions, including DAGL- $\alpha$, FAAH, ABHD12, MAGL, ABHD6, and ABHD4 (see Figure 3 for a heat map). Eleven enzymes reacted with both probes. A high correlation was found between the quantified enzymatic activities for each probe (Pearson's correlation of $0.86(P<0.0001))$, indicating that probe-independent protein activity was measured (Figure 3). The fluorophosphonate-based $\mathrm{ABP}$ targeted 14 unique proteins, including MAGL and $\mathrm{FAAH}$, whereas the $\beta$-lactonebased $A B P$ MB108 targeted seven unique proteins including $\mathrm{ABHD} 4, \mathrm{ABHD} 12$, and DAGL- $\alpha$. ABHD4 showed an equal activity across all brain regions, while FAAH had the highest activity in the hippocampus and frontal cortex. The activity of DAGL- $\alpha$ in the cerebellum was $\sim 2$-fold higher compared to the striatum, hippocampus, and frontal cortex. Interestingly, MAGL activity was lowest in the cerebellum. The results from the chemoproteomic analysis were in line with the gel-based ABPP method, except for ABHD6, which is likely to be caused by band overlap in the gel-based assay. Further detailed analysis showed that overall relative enzymatic activities followed the same trends as observed for the protein abundance derived from a global proteomics data set published by Sharma et al. ${ }^{29}$ (Supporting Figure 1). However, several pronounced differences were detected. These different intensity profiles for activity and protein abundance may suggest that protein activity is regulated by post-translational modifications. For example, the activity of ABHD12 was equally distributed over the four brain regions, while $\mathrm{ABHD} 12$ abundance in the hippocampus was twice as high as in the cerebellum, frontal cortex and striatum. These different profiles might be explained by a down regulation of ABHD12 activity in the hippocampus. DAGL- $\alpha$ activity was highest in the cerebellum, while its relative activity in the frontal cortex was $47.2 \pm 8.6 \%, 64.6 \pm 9.0 \%$ in the hippocampus and $36.3 \pm 5.4 \%$ in the striatum. In contrast, global proteomics data showed the highest abundance of DAGL- $\alpha$ in the hippocampus, while less than $30 \%$ was found in the cerebellum, frontal cortex, and striatum. To investigate this apparent discrepancy, we have performed a Western blot analysis to check the DAGL- $\alpha$ protein levels in the four brain regions of our mice. We observed relatively high DAGL- $\alpha$ abundance in the cerebellum (Supporting Figure 2), which matched the relative activity as measured with our ABPP method.

Many other serine hydrolases were detected next to the endocannabinoid hydrolases (Figure 3). Marked differences in activity between the brain regions were observed for some of these enzymes. For example, acetylcholinesterase (ACHE), which is responsible for acetylcholine hydrolysis, showed over 10 -fold activity in the striatum compared to the other three brain regions. $\mathrm{ABHD} 16 \mathrm{~A}$, which is a phosphatidylserine lipase producing lyso-phosphatidyl-serine, ${ }^{42}$ demonstrated $\sim 2$-fold increased activity in the cerebellum compared to other brain regions. Platelet-activating factor acetylhydrolase (PLA2G7), which cleaves the $s n-2$ acetyl of acetyl-glyceryl-ether-phosphorylcholine, showed an approximate 3-fold higher activity in the cerebellum compared to the other brain regions. ${ }^{43}$

Comparison of $\mathrm{CB}_{1}^{+/+}$and $\mathrm{CB}_{1}^{-1-}$ Brain Regions. Next, the regulatory control of the $C_{1}$ receptor over basal production and degradation of endocannabinoids was investigated. To this end, the enzymatic activity of hydrolases involved in endocannabinoid biosynthesis and degradation in the cerebellum, hippocampus, frontal cortex, and striatum of $\mathrm{CB}_{1}$ receptor knockout mice was compared to their wild-type counterparts. Fluorescent scanning of gels from ABPP experiments using MB064 and FP-TAMRA did not reveal any difference in labeling patterns in the brain regions (Figure 4).

To investigate in depth the effect of $\mathrm{CB}_{1}$ receptor deletion on serine hydrolase activity, the chemoproteomic assay in the four mouse brain regions was performed. The relative activities of 36 different hydrolases were detected and quantified (Figure 5). No difference in the enzymatic activity of the 2-AG biosynthetic enzyme (DAGL- $\alpha$ ) and the 2-AG catabolic enzymes ABHD6, $A B H D 12$, and MAGL was observed in the cerebellum, frontal cortex, hippocampus, or striatum. Nor were any changes observed in ABHD4 and FAAH activities. 

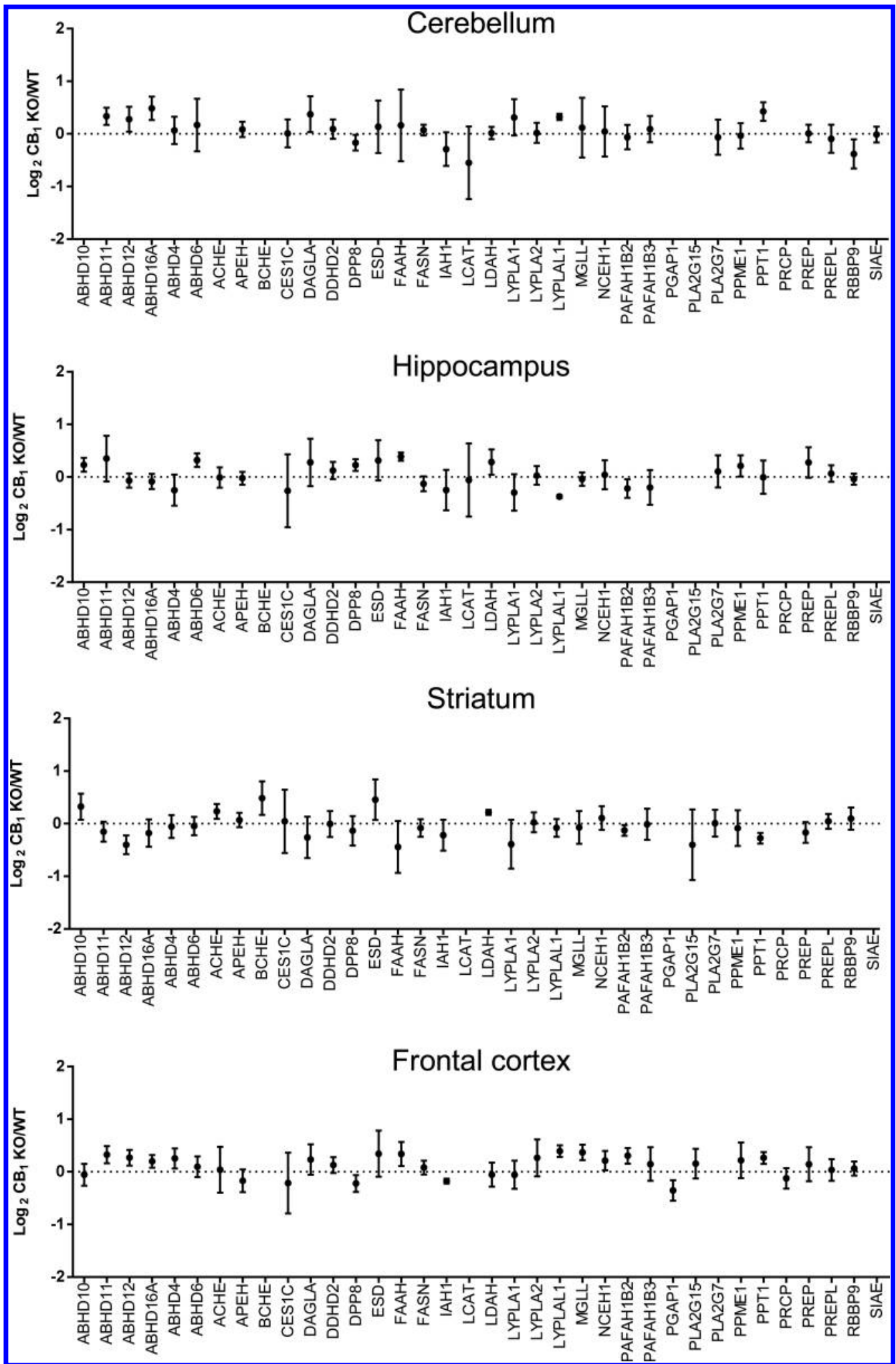

Figure 5. Comparison of enzyme activity in $\mathrm{CB}^{+/+}$and $\mathrm{CB} 1^{-/-}$mouse brain regions. $\log _{2}$ ratio of enzyme activity in $\mathrm{CB} 1^{-/-}$brain regions compared to $\mathrm{CB}^{+/+}$(mean $\left.\pm \mathrm{SD}\right)$. Activity is measured by activity-based proteomics using FP-biotin $(10 \mu \mathrm{M})$ and MB108 $(10 \mu \mathrm{M})$. Combined data from both activity based probes ( $n=4$ for each brain region). Statistical analysis by means of one-way ANOVA, each CB1 WT/KO ratio was compared to a $\log _{2}$ ratio of 0 ; subsequently the $p$ values were subjected to Benjamini Hochberg correction. Setting the false discovery rate at $10 \%$.

\section{DISCUSSION}

The enzymes responsible for endocannabinoid biosynthesis and degradation tightly regulate endocannabinoid $\mathrm{CB}_{1}$ receptor activation. A fluorescence and chemoproteomic ABPP assay was employed to quantify the activity of hydrolases in the cerebellum, hippocampus, striatum, and frontal cortex to gain more insight in the spatiotemporal control of $\mathrm{CB}_{1}$ receptormediated physiology. ABPP relies on the mechanism-based 
formation of a covalent bond between the $\mathrm{ABP}$ and the catalytic nucleophile of its target enzyme. Therefore, the abundance of only active enzymes is monitored by ABPP. The gel-based fluorescence assay has a relatively short experimental time $(\sim 3 \mathrm{~h})$ and has the ability to retrieve information on differences in protein migration on SDS-PAGE caused by, e.g., phosphorylation, glycosylation, or proteolysis. The chemoproteomic methodology is complementary and directly reports on the identity and activity of a large number of enzymes in parallel in their native environment with all post-translational modifications in place.

Previous studies have indicated the importance of analyzing different brain regions when studying the endocannabinoid system. Endocannabinoid levels have been shown to vary between brain regions. Moreover, the $C_{1}$ receptor and the endocannabinoid regulatory machinery do not present a homogeneous expression across brain regions. ${ }^{1,26,29,44}$ These variations are confirmed in the comparative ABPP approach using cerebellum, hippocampus, frontal cortex, and striatum. Significant differences were found in the enzyme activity of DAGL- $\alpha$, MAGL, ABHD6, and FAAH between different brain regions. For instance, the highest FAAH activity was observed in the hippocampus, which is in line with previous reports indicating that the hippocampus has the highest FAAH expression levels, highest AEA levels, and turnover rate compared to other brain regions. ${ }^{18,21,26}$ These observations suggest that AEA has an important physiological role in the hippocampus, such as providing "on demand" $\mathrm{CB}_{1}$ receptordependent neuroprotection against excitotoxicity. ${ }^{45}$ Next to its role as an endocannabinoid, AEA functions also as an endogenous agonist of the TRPV1 ion channel. ${ }^{46}$ It could be envisioned that FAAH not only terminates $\mathrm{CB}_{1}$ receptor signaling but also limits TRPV1 signaling by AEA in the hippocampus. In this respect, it would be interesting to investigate whether TRPV1 mediates crosstalk between AEA and 2-AG biosynthesis as was previously observed in the striatum. ${ }^{47}$ Of note, FAAH does not only inactivate AEA but uses a wide range of long chain fatty acid amides as substrates. The physiological role of these endogenous signaling lipids is poorly understood, but the hippocampus would be an excellent brain region in which to investigate their biological role.

DAGL- $\alpha$ activity was $\sim 2$ fold higher in the cerebellum compared to the frontal cortex, striatum, and hippocampus. The activity of MAGL in the cerebellum was only $23.3 \pm 11 \%$ of the total MAGL activity in the frontal cortex. In addition, no relative compensatory activity of ABHD6 and ABHD12 was observed in the cerebellum (Figure 2). Yet, 2-AG levels are not substantially higher in the cerebellum. ${ }^{21,26,48}$ This may suggest that 2-AG levels and $\mathrm{CB}_{1}$ receptor activity are controlled by MAGL, rather than by 2-AG biosynthesis, or that other catabolic pathways, such as oxidative catabolism, could play a role in this brain region.

Comparison of the activity-based proteomics data with protein expression values from the literature showed an overall correlation. For several enzymes (e.g., ABHD16A, ABHD10, ABHD12), however, the activity profile did not match the protein abundance profile as reported in a global proteomics data set. ${ }^{29}$ This may indicate that the activity of these proteins is regulated by post-translational modifications or could result from differences in the protein expression due to variation in age and mouse species analyzed in the various studies (as observed with DAGL- $\alpha$ ).
Previous studies have investigated the effect of $\mathrm{CB}_{1}$ receptor modulation by pharmacological or genetic means on endocannabinoid levels. ${ }^{18,21-26}$ Here, this question was revisited, and the ABPP-methodology was employed to study the effect of genetic deletion of the $C_{1}$ receptor on endocannabinoid hydrolase activity in various brain regions. No significant differences in the activity of endocannabinoid biosynthetic and catabolic enzymes between $\mathrm{CB}_{1} \mathrm{KO}$ and $\mathrm{WT}$ brain regions were observed. These results are in line with previous reports. ${ }^{26,18}$ Yet, it cannot be excluded that specific $\mathrm{CB}_{1}$ receptor populations might increase production and/or degradation while others might decrease it, leading to a lack of change when removing all these receptor populations. In support of this hypothesis is the observation that within the frontal cortex the turnover of 2-AG is decreased and increased in mutant mice lacking $\mathrm{CB}_{1}$ receptors on principal neurons (possibly glutamatergic) and on astrocytes, respectively. ${ }^{18}$

Of note, the applied technique has several limitations. The total enzyme activity is measured by an end point measurement using a covalent inhibitor. Therefore, small changes in the $K_{\mathrm{M}}$ as a result of post-translational modifications are difficult to monitor by ABPP. Additionally, although the proteomics assay is capable of detecting a wide array of hydrolases that play an important role in regulation of endocannabinoid signaling, this methodology is not compatible with enzymes that do not form a covalent intermediate with their substrate, such as the $\beta$ metallo-lactamase NAPE-PLD. Importantly, other mechanisms that regulate endocannabinoid signaling, such as the putative endocannabinoid transporter proteins and oxidative metabolism of endocannabinoids toward eicosanoids, are not taken into account by the ABPP-method.

In conclusion, we have employed an ABPP method that can measure the activity of six different enzymes with endocannabinoid hydrolase activity in their native setting in a single experiment. This methodology was used to map endocannabinoid hydrolase activity in the cerebellum, striatum, frontal cortex, and cerebellum. This revealed brain region specific differences in endocannabinoid hydrolase activity. The method was applied to study the effect of genetic deletion of the $C_{1}$ receptor in these brain regions. The results indicate that the CB1 does not exert regulatory control over the basal production and degradation of endocannabinoids and that genetic deletion of the $C_{1}$ receptor does not induce any compensatory mechanism in endocannabinoid hydrolase activity.

\section{METHODS}

Animals. The experiments were conducted in strict compliance with European directives and French laws on animal experimentation (authorization number C33 12024 to F.C. from the French Ministry of Agriculture). The experiments were conducted on brains of male $\mathrm{CB}_{1}$ WT and KO mice that were sacrificed at the age of 8-9 weeks. The mice were bred at the NeuroCentre INSERM U862.

Preparation of Mouse Tissue Proteome. The mouse brain regions, hippocampus, striatum, cerebellum, and frontal cortex, were slowly thawed on ice. The thawed mouse brain regions were dounce homogenized in cold $\left(4^{\circ} \mathrm{C}\right) \mathrm{pH} 7.2$ lysis buffer A $(20 \mathrm{mM}$ HEPES at $\mathrm{pH} 7.2,2 \mathrm{mM}$ DTT, $1 \mathrm{mM} \mathrm{MgCl}, 25 \mathrm{U} / \mathrm{mL}$ Benzonase) and incubated for $5 \mathrm{~min}$ on ice. The suspension was centrifuged $(2500 \mathrm{~g}, 3$ min, $4{ }^{\circ} \mathrm{C}$ ) to remove debris. The supernatant was collected and subjected to ultracentrifugation $\left(100.000 \mathrm{~g}, 45 \mathrm{~min}, 4{ }^{\circ} \mathrm{C}\right.$, Beckman Coulter, Type Ti70 rotor). This yielded the membrane fraction as a pellet and the cytosolic fraction in the supernatant. The supernatant was collected, and the membrane fraction was suspended in storage 
buffer (20 mM HEPES at $\mathrm{pH} 7.2,2 \mathrm{mM} \mathrm{DTT}$ ). The total protein concentration was determined with Quick Start Bradford assay (Biorad) or Qubit protein assay (Invitrogen). Membranes and supernatant fractions were both diluted to a total protein concentration of $0.5 \mathrm{mg} \mathrm{mL}^{-1}$ and were used directly or flash frozen in liquid nitrogen and stored in aliquots at $-80{ }^{\circ} \mathrm{C}$ until use.

Activity-based Protein Profiling. Mouse hippocampus, striatum, cerebellum, or frontal cortex $\left(0.5 \mathrm{mg} \mathrm{mL}{ }^{-1}\right)$ were incubated with activity-based probe MB064 (250 nM) or TAMRA-FP (500 nM) for $20 \mathrm{~min}$. At room temperature, Laemlli buffer was added to quench the protein activity, and the mixture was allowed to stand at room temperature for $30 \mathrm{~min}$ before the samples were loaded and resolved on SDS page gel (10\% acrylamide). The gels were scanned using a ChemiDoc MP system (Cy3 settings, 605/50 filter) and analyzed using Image lab 4.1. After fluorescent scanning, the gels were stained with a coomassie staining solution. After destaining, the gels were scanned, and protein loading was quantified using image lab 4.1. Gel fluorescence intensities were corrected for protein abundance (loading control).

Proteomics. Proteomics experiments were performed in a similar fashion to those reported previously. ${ }^{38} \mathrm{~A}$ detailed protocol is given in the Supporting Information.

Statistical Analysis. Statistical analysis for mouse brain WT versus $\mathrm{CB}_{1}$ knockout screen was performed. For proteins identified by both probes, the normalized ratios from Maxquant were combined for further analysis. Using GraphPad Prism 7.0 software, the binary logarithm of each ratio was compared to 0 with one-way ANOVA. The resulting $p$ values were subjected to a Benjamini-Hochberg correction, setting the false discovery rate at $10 \%(q=0.1)$. Briefly, the $p$ values of all quantifiable hits were ordered from lowest to highest, and the Benjamini-Hochberg statistic was calculated as $q *$ (position in the list) divided by the number of tests. Subsequently, the proteins for which the $p$ value is smaller than the $\mathrm{BH}$ statistic are controlled for an FDR of $q^{*} 10 \%$.

\section{ASSOCIATED CONTENT}

\section{S Supporting Information}

The Supporting Information is available free of charge on the ACS Publications website at DOI: 10.1021/acschembio.6b01052.
Supporting Table 1 (XLSX)
Supporting Table 2 (XLSX)
Supporting Table 3 (XLSX)
Supporting Table 4 (XLSX)
Supporting Methods, Supporting Figures 1 and 2, Supporting Tables 1 and 2 (PDF)

\section{AUTHOR INFORMATION}

\section{Corresponding Author}

*E-mail: m.van.der.stelt@chem.leidenuniv.nl.

\section{ORCID}

Marc P. Baggelaar: 0000-0002-9784-6250

\section{Author Contributions}

"Contributed equally

\section{Notes}

The authors declare no competing financial interest.

\section{REFERENCES}

(1) Mechoulam, R., and Parker, L. A. (2013) The endocannabinoid system and the brain. Annu. Rev. Psychol. 64, 21-47.

(2) Dalton, G. D., and Howlett, A. C. (2012) Cannabinoid CB1 receptors transactivate multiple receptor tyrosine kinases and regulate serine/threonine kinases to activate ERK in neuronal cells. Br. I. Pharmacol. 165, 2497-2511.
(3) Howlett, A. C., Barth, F., Bonner, T. I., Cabral, G., Casellas, P., Devane, W. A., Felder, C. C., Herkenham, M., Mackie, K., Martin, B. R, Mechoulam, R. and Pertwee, R. G. (2002) International Union of Pharmacology. XXVII. Classification of cannabinoid receptors. Pharmacol. Rev. 54, 161-202.

(4) Ahn, K., McKinney, M. K., and Cravatt, B. F. (2008) Enzymatic pathways that regulate endocannabinoid signaling in the nervous system. Chem. Rev. 108, 1687-1707.

(5) Di Marzo, V. (2011) Endocannabinoid signaling in the brain: biosynthetic mechanisms in the limelight. Nat. Neurosci. 14, 9-15.

(6) Piomelli, D. (2014) More surprises lying ahead. The endocannabinoids keep us guessing. Neuropharmacology 76 (B), 228-234.

(7) Pacher, P., Batkai, S., and Kunos, G. (2006) The endocannabinoid system as an emerging target of pharmacotherapy. Pharmacol. Rev. 58, 389-462.

(8) Di Marzo, V., Bifulco, M., and De Petrocellis, L. (2004) The endocannabinoid system and its therapeutic exploitation. Nat. Rev. Drug Discovery 3, 771-784.

(9) Gao, Y., Vasilyev, D. V., Goncalves, M. B., Howell, F. V., Hobbs, C., Reisenberg, M., Shen, R., Zhang, M. Y., Strassle, B. W., Lu, P., Mark, L., Piesla, M. J., Deng, K., Kouranova, E. V., Ring, R. H., Whiteside, G. T., Bates, B., Walsh, F. S., Williams, G., Pangalos, M. N., Samad, T. A., and Doherty, P. (2010) Loss of retrograde endocannabinoid signaling and reduced adult neurogenesis in diacylglycerol lipase knock-out mice. I. Neurosci. 30, 2017-2024.

(10) Tanimura, A., Yamazaki, M., Hashimotodani, Y., Uchigashima, M., Kawata, S., Abe, M., Kita, Y., Hashimoto, K., Shimizu, T., Watanabe, M., Sakimura, K., and Kano, M. (2010) The Endocannabinoid 2-Arachidonoylglycerol Produced by Diacylglycerol Lipase alpha Mediates Retrograde Suppression of Synaptic Transmission. Neuron 65, 320-327.

(11) Murataeva, N., Straiker, A., and Mackie, K. (2014) Parsing the players: 2-arachidonoylglycerol synthesis and degradation in the CNS. Br. I. Pharmacol. 171, 1379-1391.

(12) Di Marzo, V., Fontana, A., Cadas, H., Schinelli, S., Cimino, G., Schwartz, J. C., and Piomelli, D. (1994) Formation and inactivation of endogenous cannabinoid anandamide in central neurons. Nature 372, 686-691.

(13) Sun, Y. X., Tsuboi, K., Okamoto, Y., Tonai, T., Murakami, M., Kudo, I., and Ueda, N. (2004) Biosynthesis of anandamide and Npalmitoylethanolamine by sequential actions of phospholipase A2 and lysophospholipase D. Biochem. I. 380, 749-756.

(14) Tsuboi, K., Okamoto, Y., Rahman, I. A., Uyama, T., Inoue, T., Tokumura, A., and Ueda, N. (2015) Glycerophosphodiesterase GDE4 as a novel lysophospholipase $\mathrm{D}$ : a possible involvement in bioactive $\mathrm{N}$ acylethanolamine biosynthesis. Biochim. Biophvs. Acta, Mol. Cell Biol. Lipids 1851, 537-548.

(15) Liu, J., Wang, L., Harvey-White, J., Huang, B. X., Kim, H. Y., Luquet, S., Palmiter, R. D., Krystal, G., Rai, R., Mahadevan, A., Razdan, R. K., and Kunos, G. (2008) Multiple pathways involved in the biosynthesis of anandamide. Neuropharmacology 54, 1-7.

(16) Rahman, I. A. S., Tsuboi, K., Uyama, T., and Ueda, N. (2014) New players in the fatty acyl ethanolamide metabolism. Pharmacol. Res. $86,1-10$.

(17) Cravatt, B. F., Giang, D. K., Mayfield, S. P., Boger, D. L., Lerner, R. A., and Gilula, N. B. (1996) Molecular characterization of an enzyme that degrades neuromodulatory fatty-acid amides. Nature 384 , $83-87$.

(18) Belluomo, I., Matias, I., Pernegre, C., Marsicano, G., and Chaouloff, F. (2015) Opposite control of frontocortical 2arachidonoylglycerol turnover rate by cannabinoid type- 1 receptors located on glutamatergic neurons and on astrocytes. L. Neurochem. 133, 26-37.

(19) Starke, K., Gothert, M., and Kilbinger, H. (1989) Modulation of neurotransmitter release by presynaptic autoreceptors. Physiol. Rev. 69, 864-989. 
(20) Langer, S. Z. (1997) 25 years since the discovery of presynaptic receptors: present knowledge and future perspectives. Trends Pharmacol. Sci. 18, 95-99.

(21) Di Marzo, V., Breivogel, C. S., Tao, Q., Bridgen, D. T., Razdan, R. K., Zimmer, A. M., Zimmer, A., and Martin, B. R. (2000) Levels, metabolism, and pharmacological activity of anandamide in CB1 cannabinoid receptor knockout mice: Evidence for non-CB1, non-CB2 receptor-mediated actions of anandamide in mouse brain. I. Neurochem. 75, 2434-2444.

(22) Di Marzo, V., Berrendero, F., Bisogno, T., Gonzalez, S., Cavaliere, P., Romero, J., Cebeira, M., Ramos, J. A., and FernandezRuiz, J. J. (2000) Enhancement of anandamide formation in the limbic forebrain and reduction of endocannabinoid contents in the striatum of Delta(9)-tetrahydrocannabinol-tolerant rats. L. Neurochem. 74, $1627-1635$.

(23) Maccarrone, M., Attina, M., Bari, M., Cartoni, A., Ledent, C., and Finazzi-Agro, A. (2001) Anandamide degradation and Nacylethanolamines level in wild-type and CB1 cannabinoid receptor knockout mice of different ages. [. Neurochem. 78, 339-348.

(24) Maccarrone, M., Valverde, O., Barbaccia, M. L., Castane, A., Maldonado, R., Ledent, C., Parmentier, M., and Finazzi-Agro, A. (2002) Age-related changes of anandamide metabolism in CB1 cannabinoid receptor knockout mice: correlation with behaviour. Eur. I. Neurosci. 15, 1178-1186.

(25) Bequet, F., Uzabiaga, F., Desbazeille, M., Ludwiczak, P., Maftouh, M., Picard, C., Scatton, B., and Le Fur, G. (2007) CB1 receptor-mediated control of the release of endocannabinoids (as assessed by microdialysis coupled with LC/MS) in the rat hypothalamus. Eur. I. Neurosci. 26, 3458-3464.

(26) Leishman, E., Cornett, B., Spork, K., Straiker, A., Mackie, K., and Bradshaw, H. B. (2016) Broad impact of deleting endogenous cannabinoid hydrolyzing enzymes and the CB1 cannabinoid receptor on the endogenous cannabinoid-related lipidome in eight regions of the mouse brain. Pharmacol. Res. 110, 159-172.

(27) Schlosburg, J. E., Blankman, J. L., Long, J. Z., Nomura, D. K., Pan, B., Kinsey, S. G., Nguyen, P. T., Ramesh, D., Booker, L., Burston, J. J., Thomas, E. A., Selley, D. E., Sim-Selley, L. J., Liu, Q. S., Lichtman, A. H., and Cravatt, B. F. (2010) Chronic monoacylglycerol lipase blockade causes functional antagonism of the endocannabinoid system. Nat. Neurosci. 13, 1113-1119.

(28) Kang, H. J., Kawasawa, Y. I., Cheng, F., Zhu, Y., Xu, X. M., Li, M. F., Sousa, A. M. M., Pletikos, M., Meyer, K. A., Sedmak, G., Guennel, T., Shin, Y., Johnson, M. B., Krsnik, Z., Mayer, S., Fertuzinhos, S., Umlauf, S., Lisgo, S. N., Vortmeyer, A., Weinberger, D. R., Mane, S., Hyde, T. M., Huttner, A., Reimers, M., Kleinman, J. E., and Sestan, N. $(2011)$ Spatio-temporal transcriptome of the human brain. Nature 478, 483-489.

(29) Sharma, K., Schmitt, S., Bergner, C. G., Tyanova, S., Kannaiyan, N., Manrique-Hoyos, N., Kongi, K., Cantuti, L., Hanisch, U. K., Philips, M. A., Rossner, M. J., Mann, M., and Simons, M. (2015) Cell type- and brain region-resolved mouse brain proteome. Nat. Neurosci. $18,1819-1831$.

(30) Lein, E. S., Hawrylycz, M. J., Ao, N., Ayres, M., Bensinger, A., Bernard, A., Boe, A. F., Boguski, M. S., Brockway, K. S., Byrnes, E. J., Chen, L., Chen, L., Chen, T. M., Chi Chin, M., Chong, J., Crook, B. E., Czaplinska, A., Dang, C. N., Datta, S., Dee, N. R., Desaki, A. L., Desta, T., Diep, E., Dolbeare, T. A., Donelan, M. J., Dong, H. W., Dougherty, J. G., Duncan, B. J., Ebbert, A. J., Eichele, G., Estin, L. K., Faber, C., Facer, B. A., Fields, R., Fischer, S. R., Fliss, T. P., Frensley, C., Gates, S. N., Glattfelder, K. J., Halverson, K. R., Hart, M. R., Hohmann, J. G., Howell, M. P., Jeung, D. P., Johnson, R. A., Karr, P. T., Kawal, R., Kidney, J. M., Knapik, R. H., Kuan, C. L., Lake, J. H., Laramee, A. R., Larsen, K. D., Lau, C., Lemon, T. A., Liang, A. J., Liu, Y., Luong, L. T., Michaels, J., Morgan, J. J., Morgan, R. J., Mortrud, M. T., Mosqueda, N. F., Ng, L. L., Ng, R., Orta, G. J., Overly, C. C., Pak, T. H., Parry, S. E., Pathak, S. D., Pearson, O. C., Puchalski, R. B., Riley, Z. L., Rockett, H. R., Rowland, S. A., Royall, J. J., Ruiz, M. J., Sarno, N. R., Schaffnit, K., Shapovalova, N. V., Sivisay, T., Slaughterbeck, C. R., Smith, S. C., Smith, K. A., Smith, B. I., Sodt, A. J., Stewart, N. N., Stumpf, K. R.,
Sunkin, S. M., Sutram, M., Tam, A., Teemer, C. D., Thaller, C., Thompson, C. L., Varnam, L. R., Visel, A., Whitlock, R. M., Wohnoutka, P. E., Wolkey, C. K., Wong, V. Y., Wood, M., Yaylaoglu, M. B., Young, R. C., Youngstrom, B. L., Feng Yuan, X., Zhang, B., Zwingman, T. A., and Jones, A. R. (2007) Genome-wide atlas of gene expression in the adult mouse brain. Nature 445, 168176.

(31) Vogel, C., and Marcotte, E. M. (2012) Insights into the regulation of protein abundance from proteomic and transcriptomic analyses. Nat. Rev. Genet. 13, 227-232.

(32) Kobe, B., and Kemp, B. E. (1999) Active site-directed protein regulation. Nature 402, 373-376.

(33) Dotsey, E. Y., Jung, K. M., Basit, A., Wei, D., Daglian, J., Vacondio, F., Armirotti, A., Mor, M., and Piomelli, D. (2015) Peroxide-Dependent MGL Sulfenylation Regulates 2-AG-Mediated Endocannabinoid Signaling in Brain Neurons. Chem. Biol. 22, 619628.

(34) Shonesy, B. C., Wang, X., Rose, K. L., Ramikie, T. S., Cavener, V. S., Rentz, T., Baucum, A. J., 2nd, Jalan-Sakrikar, N., Mackie, K., Winder, D. G., Patel, S., and Colbran, R. J. (2013) CaMKII regulates diacylglycerol lipase-alpha and striatal endocannabinoid signaling. Neurosci. 16, 456-463.

(35) Bisogno, T., Howell, F., Williams, G., Minassi, A., Cascio, M. G., Ligresti, A., Matias, I., Schiano-Moriello, A., Paul, P., Williams, E. J., Gangadharan, U., Hobbs, C., Di Marzo, V., and Doherty, P. (2003) Cloning of the first sn1-DAG lipases points to the spatial and temporal regulation of endocannabinoid signaling in the brain. L. Cell Biol. 163, $463-468$.

(36) Cravatt, B. F., Wright, A. T., and Kozarich, J. W. (2008) Activity-based protein profiling: from enzyme chemistry to proteomic chemistry. Annu. Rev. Biochem. 77, 383-414.

(37) Niphakis, M. J., and Cravatt, B. F. (2014) Enzyme inhibitor discovery by activity-based protein profiling. Annu. Rev. Biochem. 83, 341-377.

(38) Baggelaar, M. P., Chameau, P. J., Kantae, V., Hummel, J., Hsu, K. L., Janssen, F., van der Wel, T., Soethoudt, M., Deng, H., den Dulk, H., Allara, M., Florea, B. I., Di Marzo, V., Wadman, W. J., Kruse, C. G., Overkleeft, H. S., Hankemeier, T., Werkman, T. R., Cravatt, B. F., and van der Stelt, M. (2015) Highly Selective, Reversible Inhibitor Identified by Comparative Chemoproteomics Modulates Diacylglycerol Lipase Activity in Neurons. I. Am. Chem. Soc. 137, 8851-8857.

(39) Liu, Y., Patricelli, M. P., and Cravatt, B. F. (1999) Activity-based protein profiling: the serine hydrolases. Proc. Natl. Acad. Sci. U. S. A 96, 14694-14699.

(40) Baggelaar, M. P., Janssen, F. J., van Esbroeck, A. C., den Dulk, H., Allara, M., Hoogendoorn, S., McGuire, R., Florea, B. I., Meeuwenoord, N., van den Elst, H., van der Marel, G. A., Brouwer, J., Di Marzo, V., Overkleeft, H. S., and van der Stelt, M. (2013) Development of an activity-based probe and in silico design reveal highly selective inhibitors for diacylglycerol lipase-alpha in brain. Anoew. Chem., Int. Ed. 52, 12081-12085.

(41) Cox, J., and Mann, M. (2008) MaxQuant enables high peptide identification rates, individualized p.p.b.-range mass accuracies and proteome-wide protein quantification. Nat. Biotechnol. 26, 1367-1372.

(42) Kamat, S. S., Camara, K., Parsons, W. H., Chen, D. H., Dix, M. M., Bird, T. D., Howell, A. R., and Cravatt, B. F. (2015) Immunomodulatory lysophosphatidylserines are regulated by ABHD16A and ABHD12 interplay. Nat. Chem. Biol. 11, 164-171.

(43) Long, J. Z., and Cravatt, B. F. (2011) The metabolic serine hydrolases and their functions in mammalian physiology and disease. Chem. Rev. 111, 6022-6063.

(44) Herkenham, M., Lynn, A. B., Little, M. D., Johnson, M. R., Melvin, L. S., de Costa, B. R., and Rice, K. C. (1990) Cannabinoid receptor localization in brain. Proc. Natl. Acad. Sci. U. S. A. 87, 19321936.

(45) Marsicano, G., Goodenough, S., Monory, K., Hermann, H., Eder, M., Cannich, A., Azad, S. C., Cascio, M. G., Gutierrez, S. O., van der Stelt, M., Lopez-Rodriguez, M. L., Casanova, E., Schutz, G., Zieglgansberger, W., Di Marzo, V., Behl, C., and Lutz, B. (2003) CB1 
cannabinoid receptors and on-demand defense against excitotoxicity. Science 302, 84-88.

(46) van der Stelt, M., Trevisani, M., Vellani, V., De Petrocellis, L., Schiano Moriello, A., Campi, B., McNaughton, P., Geppetti, P., and Di Marzo, V. (2005) Anandamide acts as an intracellular messenger amplifying Ca2 ${ }^{+}$influx via TRPV1 channels. EMBO I. 24, 3026-3037. (47) Maccarrone, M., Rossi, S., Bari, M., De Chiara, V., Fezza, F., Musella, A., Gasperi, V., Prosperetti, C., Bernardi, G., Finazzi-Agro, A., Cravatt, B. F., and Centonze, D. (2008) Anandamide inhibits metabolism and physiological actions of 2-arachidonoylglycerol in the striatum. Nat. Neurosci. 11, 152-159.

(48) Buczynski, M. W., and Parsons, L. H. (2010) Quantification of brain endocannabinoid levels: methods, interpretations and pitfalls. $\underline{B}$. I. Pharmacol. 160, 423-442. 